Journal of Agricultural Sciences
(Tarim Bilimleri Dergisi)

\title{
Detection of Metabolite Content in Local Bitter White Lupin Seeds (Lupinus albus L.) and Acaricidal and Insecticidal Effect of its Seed Extract
}

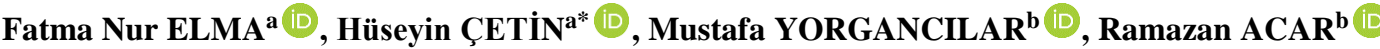 \\ ${ }^{a}$ Selçuk University, Faculty of Agriculture, Department of Plant Protection, Konya, TURKEY

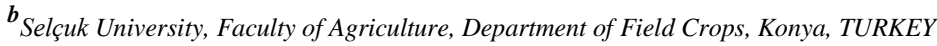

\section{ARTICLE INFO}

Research Article

Corresponding Author: Huseyin CETIN, E-mail: hcetin@selcuk.edu.tr

Received: 19 September 2019 / Revised Form: 09 May 2020 / Accepted: 09 June 2020 / Online: 04 December 2021

\section{ABSTRACT}

This study investigated the acaricidal and insecticidal effect of local lupin (Lupinus albus L. Fabaceae) seed extract against Tetranychus urticae Koch (Acari: Tetranychidae), Callosobruchus maculatus F. (Coleoptera: Chrysomelidae), Plodia interpunctella (Hubner) (Lepidoptera: Pyralidae) and metabolite content of seeds. In tests for T. urticae leaf-disk bioassay was employed. Contrarily, two $\mu \mathrm{L}$ of the $L$. albus extract were topically applied using a micro-applicator on $C$. maculatus and $P$. interpunctella. In the assays of $T$. urticae and $P$. interpunctella, the concentrations of $0.78,1.56,3.12,6.25,12.5,25 \%(\mathrm{w} / \mathrm{w})$ of the plant extracts were used Furthermore, the concentrations of $0.625,1.25,2.50,5,10 \%(\mathrm{w} / \mathrm{w})$ were applied to C. maculatus. Mortality data was collected 24, 48 and 72 hours after application. In the results, L. albus extract was found to be quite effective to $C$. maculatus adults with $\mathrm{LD}_{50}$ of $7.26,1.21$ and $0.55 \%$ after 24, 48 and 72 hours, respectively. Moreover, lupin extract was effective to $T$. urticae adults with $\mathrm{LC}_{50}$ values of $4.03,3.15$ and $2.73 \%$ for the same durations. L. albus extract was showed low insecticidal effect against the larvae of $P$. interpunctella.

In seeds metabolite content were detected, which contained 686.99 mg GAE / $100 \mathrm{mg}$ total phenol, $22.06 \mathrm{mg} \mathrm{QE} \mathrm{/} 100 \mathrm{mg}$ total flavonoid, DPPH $26.04 \mathrm{mg}$ TE / $100 \mathrm{~g}$ having antioxidant activity. The bitter taste of stem and seeds of the plant is due to their metabolite content which has a toxic effect.

In conclusion, results indicated that lupin seed has a high secondary metabolites content and also its extract had the high toxic effect against T. urticae and C. maculatus.

Keywords: Callosobruchus maculatus, Tetranychus urticae, Plodia interpunctella; Lupinus albus extract, Metabolite content

(C) Ankara University, Faculty of Agriculture

\section{Introduction}

Pests have a negative effect on the growth of culture plants grown in greenhouses and fields, resulting in the loss of stored products. Tetranychus urticae Koch (Acarina: Tetranychidae) is a major polyphagous pest that damages many agricultural crops both in the field and in greenhouses.

Callosobruchus maculatus F. (Coleoptera: Chrysomelidae) is a major pest especially for legumes and are able to survive both in the storages and in the field.

Plodia interpunctella (Hubner) (Lepidoptera: Pyralidae) is a major pest for grain and grain products with dried fruits being the main ones, as well as for processed and non-processed products like milk powder, corn flour, wheat flour.

Synthetic chemical pesticides have been used widely in pest management. Potential risks posed by synthetic chemical pesticides for mammals, consumer concerns regarding insecticide residues, and increased resistance of pest populations against insecticides, have encouraged researchers to discover new approaches for pest management. The approach of using plants for insecticide production has been brought up by different researchers (Gökçe et al. 2007; Erdoğan et al. 2012; Elma 2014; Ali et al. 2017). Given the destructive nature of synthetic chemical insecticides, it is critical to develop safe and environment friendly resources for better and safer pest management.

White lupin (Lupinus albus L.) is a species of the genus Lupinus in the family Leguminosae (Duranti et al. 2008). This plant is named termis, acibakla or termiye in Turkey and a local population of bitter white lupin is conventionally cultivated around lakes region.

The lupin plants have a secondary metabolite in its seeds and stem (Oomah et. al. 2006; Reinhard et al. 2006). They can deter a number of herbivores (nematodes, aphids, caterpillars, beetles, locusts, snails) (Gegear et al. 2007). Deterrent or toxic effects 
of alkaloid such as sparteine, lupanine and cytisine against phytophagous insects have been evaluated (Wink 1992; BermudezTorres et al. 2009).

In previous studies, L. albus seed extract has not been tested against C. maculatus, T. urticae and Plodia interpunctella yet. The aim of this study was to determine of metabolite content of lupin seed and evaluating the insecticidal and acaricidal activities of its extracts against $C$. maculatus, T. urticae and Plodia interpunctella.

\section{Material and Methods}

\subsection{Plant material}

Lupin seeds (local L. albus landrace) that had been cultivated in the Deştiğin/Doğanhisar district $\left(37^{\circ} 59^{\prime} \mathrm{N}, 31^{\circ} 25^{\prime} \mathrm{E}\right)$ of Konya, Turkey, in 2012, were obtained from a local seller. After this transaction, the lupin seeds were desiccated and they were cleaned manually to remove all foreign matter such as dust, dirt, stones and chaff as well as immature, broken seeds.

\subsection{Metabolite content in seeds}

Three analyzes in this section were performed in 2019 with the procurement of services in the Laboratory of Food Institute of TÜBİTAK-Marmara Research Center.

\subsubsection{Total phenolic compound (TPC)}

TPC was measured determined by spectrophotometry, using gallic acid as a standard, according the method described by Singleton \& Rossi (1965). Briefly, $0.2 \mathrm{~mL}$ of the diluted sample extract was transferred in tubes containing $1.0 \mathrm{~mL}$ of a $1 / 10$ dilution of Folin-Ciocalteu's reagent in water. After waiting for 10 minutes, $0.8 \mathrm{~mL}$ of a sodium carbonate solution (7.5\% w/v) was added to the sample. The tubes were then allowed to stand at room temperature for 30 min before absorbance at $743 \mathrm{~nm}$ was measured. The TPC was expressed as gallic acid equivalents (GAE) in $\mathrm{mg} / 100 \mathrm{~mL}$ of fruit juice. The concentration of polyphenols in samples was derived from a standard curve of gallic acid ranging from 0.2 to $4 \mathrm{mg} \mathrm{L}^{-1}$.

\subsubsection{Estimation total flavonoid}

Total flavonoid contents of lupin seed (mature) were estimated by using the aluminium nitrate colorimetric method as described by Ashokkumar et al. (2010). Quercetin was used to make the calibration curve.

\subsubsection{Total antioxidant activity}

The free radical scavenging effects of the methanol extracts were estimated according to the method of Blois (1958) with minor modifications. Antioxidant activity was found by "DPPH free radical scavenging activity method" and the results were given as "Trolox equivalent antioxidant capacity (TEAC)".

\subsection{Plant extraction}

Plant extracts were prepared as described by Gökçe et al. (2007). The dried grains were ground using a grinder (Retsch SM100) and 50-gram portions were transposed into a glass jar. Then $500 \mathrm{~mL}$ methanol (Merck 99.5\%) was supplemented. The jar was covered with aluminum foil and were left in room temperature for 6 days. At the end of this period, plant suspension was sieved using a filter paper and the liquid part was extracted and methanol was left to evaporate at low pressure at a temperature of 42 ${ }^{\circ} \mathrm{C}$ using Rotary Evaporator (Heidolp-VAP Precision). Then lupin extract was diluted using purified water and six concentrations $(0.78,1.56,3.12,6.25,12.5,25 \% \mathrm{w} / \mathrm{w})$ were prepared for $T$. urticae and P. interpunctella and five concentrations $(0.625,1.25$, $2.5,5,10 \% \mathrm{w} / \mathrm{w})$ were prepared for C. maculatus.

\subsection{Growing the insect cultures}

Callosobruchus maculatus and P. interpunctella were obtained from the stock culture rearing in the climate cabinet that operates under dark situations at a temperature of $28 \pm 1{ }^{\circ} \mathrm{C}$ and at $55 \pm 5 \% \mathrm{RH}$. On the other hand, T. urticae red form was reproduced on bean (Phaseolus vulgaris) obtained from the stock culture in the laboratory of the Plant Protection Department (the Faculty of Agriculture of Selcuk University) and grown at a temperature of $28 \pm 1{ }^{\circ} \mathrm{C}$, and at $65 \pm 5 \% \mathrm{RH}$, under a $16: 8 \mathrm{~h}$ (L: D) photoperiod.

\subsection{Toxic effect experiment}

In the experiment, the newly emerged adults ( 1 day old) of $C$. maculatus and $3^{\text {rd }}-4^{\text {th }}$-period larvae of $P$. interpunctella were used. Each concentration of the extract was applied at two $\mu \mathrm{L} /$ insect using a micro-applicator on the dorsal part of $C$. maculatus and on the dorsal abdomen of $P$. interpunctella larvae. Prior to experiment, $C$. maculatus adult and $P$. interpunctella larvae were 
immobilized by storing them for 5-10 minutes at a temperature of $2{ }^{\circ} \mathrm{C}$. The adults that completed the dripping application were placed in petri dishes and the petri dishes were held in climate cabinet until the end of the experiments. Experiment was carried out using 3 repetitions in random parcels and for each repetition, 20 adults in each petri dish were used. Only water was used for controls. Mortality data was recorded 24, 48 and 72 hours after the experiment. In the experiments for T. urticae Erdoğan et al's (2012) method was adapted. T. urticae adults were transferred into bean leaf discs placed in Petri dishes with a layer of wet cotton of $3 \mathrm{~cm}$ diameter inside. Leaf discs were dipped for ten seconds into the lupin extract and water (control) and then allowed to dry for $30 \mathrm{~min}$. Then $T$. urticae adults were transferred to leaf disc in the petri dish. Twenty adults were transferred to leaf discs. Each experimental unit $(0.78,1.56,3.12,6.25,12.5,25 \% \mathrm{w} / \mathrm{w}-)$ consisted of a glass petri dish $(10 \mathrm{~cm} \times 2 \mathrm{~cm}) \mathrm{containing}$ three leaf discs and 60 adults. Insect mortality from Petri dishes assays was appraised after 24, 48 and 72 hours of exposure.

\subsection{Data analysis}

All mortalities data were corrected for control mortality using “Abbott's formula” (Abbott 1987).

Abbotts formula $=[(\mathrm{A}-\mathrm{B}) / \mathrm{A}] \times 100$

Where; A: Live insect in control after treatment (\%); B, live insect in treated after treatment (\%). Bioassay results were analyzed using Polo-PC probit package program (LeOra Software, 1987), and confidence intervals were determined with $\mathrm{LD}_{50} / \mathrm{LC}_{50}$ and $\mathrm{LD}_{90} / \mathrm{LC}_{90}$ values.

\section{Results and Discussion}

\subsection{Metabolite content of lupin seeds}

The lupin plants have a secondary metabolite in its seeds and stem, which gives it bitterness. These metabolites include alkaloids, phenols, flavonoids, antioxidants etc. According to result of analysis, local lupin seeds contain $686.99 \mathrm{mg}$ GAE / $100 \mathrm{mg}$ total phenol, $22.06 \mathrm{mg}$ QE / $100 \mathrm{mg}$ total flavonoid, DPPH $26.04 \mathrm{mg}$ TE / $100 \mathrm{~g}$ antioxidant activity (Table 1). As can be seen here, it is seen that lupin seed has high total phenol content (TPC), flavonoid and antioxidant activity.

Table 1- Antioxidant activity, phenolic and flavonoid content in lupin seeds

\begin{tabular}{ll}
\hline Content & $m g \mathrm{l}^{-1} \mathrm{~g}^{-1}$ \\
\hline Total phenolic & 686.99 Gallic acid equivalent \\
Total flavonoid & 22.06 Quercetin equivalent \\
Total antioxidant capacity & 26.04 Trolax equivalent \\
\hline
\end{tabular}

According to Siger et al. (2012), total phenolic content (TPC) ranged between 4.92 and $7.31 \mathrm{mg}^{-1}$ dry material for cvs. Butan (L. albus) and Parys (L. luteus), respectively. TPC of the boiled legumes varied between 11.8 and $25.9 \mathrm{mg}$ GAE/100 g,

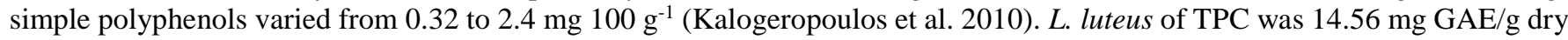
material in 6 day-long germination process provides samples (Buszewski et al. 2019). Karamac et al. (2018) white lupin and wild forms compared the phenolic content and antioxidant capacities who was found 4.36-7.24 mg GAE/g dry matter total phenolic ingredient.

Oomah et al. (2006), eight lupin (Lupinus angustifolius L.) genotypes grown at four locations in south central Alberta in 2004 were analysed for phenolic components and antioxidant activity obtained by a photochemiluminescence assay. Phenolic content in cultivars changed between 11.9 and $14.7 \mathrm{mg}$ catechin equivalent, 4.15 and $4.95 \mathrm{mg}$ routine equivalent $\mathrm{g}^{(-1)}$ lupin for TFC and flavonoid contents, respectively. Lupin cultivars displayed weak antioxidant activity based on water-soluble substances (ACW) of 0.54 to $1.07 \mathrm{mu}$ mole Antioxidant capacities TE/g with lag time varied from 70 to $153 \mathrm{~s}$ and an antioxidant index of 6.7 to 14.5 and 1.9 to $3.3 \mathrm{mu}$ mole TEAC/g based on analyses of lipid-soluble substances (ACL). In lupin genotypes, antioxidant activity was not correlated with seeds phenolic contents. Lupin, the reduced alkaloid content induced the sensibility for aphid invasion (Philippi et al. 2016).

According to these results, the local population has more phenols, flavonoids and antioxidants capacity than other genotypes. These results are the first report of the local population.

\subsection{Acaricidal effect of lupin seed extract on Tetranychus urticae Koch}

Lupin seed extract resulted in death at a rate of over $95 \%$ in all time of exposure at $25 \%$ and $12.5 \%$ concentrations. Especially at $25 \%$ concentration, $100 \%$ death rate was observed for all test periods (Table 2). 
Table 2- Mortality percent of lupin seed extract against Tetranychus urticae Koch adults at different concentrations and time of exposure

\begin{tabular}{cccc}
\hline \multicolumn{4}{c}{ Mortality $(\% \pm S E)$} \\
\hline $\begin{array}{c}\text { Concentrations } \\
(\% w / w)\end{array}$ & 24 & Time of exposure $(h)$ \\
\cline { 2 - 4 } & $100 \pm 0.00$ & 48 & 72 \\
\hline 25 & $96.43 \pm 2.92$ & $98.18 \pm 1.48$ & $100 \pm 0.00$ \\
12.50 & $67.86 \pm 4.37$ & $72.73 \pm 4.45$ & $100 \pm 0.00$ \\
6.25 & $49.99 \pm 3.86$ & $54.55 \pm 3.93$ & $57.00 \pm 1.57$ \\
3.12 & $32.14 \pm 3.86$ & $36.37 \pm 1.48$ & $42.31 \pm 8.16$ \\
1.56 & $12.50 \pm 1.46$ & $27.28 \pm 3.93$ & $28.85 \pm 4.15$ \\
0.78 & & & \\
\hline
\end{tabular}

The $\mathrm{LC}_{50}$ and $\mathrm{LC}_{90}$ values of lupin extract against the $T$. urticae are shown in Table 3. Lupin seed extract was found effective on $T$. urticae adults after 24,48 and 72 hours with $\mathrm{LC}_{50}$ of $4.03 \%, 3.15 \%$ and $2.73 \%$, respectively.

Table 3- $\mathrm{LC}_{50}$ and $\mathrm{LC}_{90}$ values and fiducial limits of lupin seed extract against Tetranychus urticae at different times

\begin{tabular}{ccccccc}
\hline $\begin{array}{c}\text { Time of } \\
\text { exposure }(h)\end{array}$ & $n^{a}$ & Slope $\pm S E$ & $\begin{array}{c}\text { LC50 } \\
\text { (Fiducial limit) }^{b}\end{array}$ & $\begin{array}{c}\text { LC90 } \\
{\text { (Fiducial limit })^{b}}^{b}\end{array}$ & Heterogeneity $^{2}$ & $\chi^{2}$ \\
\hline 24 & 360 & $0.227 \pm 0.029$ & $\begin{array}{c}4.039 \\
(3.13-4.94)\end{array}$ & $\begin{array}{c}(8.30-11.79) \\
8.981\end{array}$ & 0.86 & 13.72 \\
48 & 360 & $0.220 \pm 0.031$ & $\begin{array}{c}3.155 \\
(2.12-4.08) \\
2.733\end{array}$ & $\begin{array}{c}(7.57-11.25) \\
8.076\end{array}$ & 0.41 & 6.48 \\
72 & 360 & $0.240 \pm 0.033$ & $(1.59-3.68)$ & $(6.72-10.37)$ & 0.49 & 7.77 \\
\hline
\end{tabular}

a: Total number of tested adults; b: $95 \%$ lower and upper fiducial limits

Even though there are several studies on T. urticae regarding plant-based compounds prepared using different plants, no study carried out using Lupine seed extract has been observed in the literature. In studies regarding acaricidal effect of extracts made from different plants on T. urticae, it was observed that the resulting effect varied depending on the plant species, extract concentration and application period (Tunc \& Sahinkaya 1998; Topakc1 et al. 2005; Sertkaya et al. 2010; Topuz \& Madanlar, 2011; Chen \& Dai 2017). In our study, it was observed that the lupine plant extract resulted death rate of 50\% at above concentration starting from $3 \%$. Based on these results, it appears that lupine plant extract has a high acaricidal effect on $T$. urticae. The seeds of lupine contain lupinine, sparteine, anagyrine and angustifoline as alkaloids; they also contain lupine and vernine as glycosides (Tüzün 2013). One might conclude that the insecticidal effect of the lupine extract may be resulting from these alkaloids and secondary compounds such as glycoside. Previous studies have already demonstrated the nematicidal, molluscicidal and insecticidal effects of lupinine and sparteine (Duke 1992; Bermudez-Torres et al. 2009; Yildiz 2011).

\subsection{Insecticidal effect of lupin seed extract on callosobruchus maculatus $F$.}

Lupin seed extract resulted a mortality rate of $100 \%$ against $C$. maculatus adult at $10 \%$ concentration observed after 72 hours. Excluding the lowest application concentration over $90 \%$ mortality rate was observed using lupin extract as the data was recorded after 72 hours (Table 4).

Table 4- Mortality percent of lupin seed extract against Callosobruchus maculatus F. adults at different concentrations and time of exposure

\begin{tabular}{cccc}
\hline \multicolumn{4}{c}{ Mortality $(\% \pm S E)$} \\
\hline \multirow{3}{*}{ Concentrations $(\% w / w)$} & 24 & 48 & 72 \\
\cline { 2 - 4 } & & $91.10 \pm 2.35$ & $100 \pm 0.00$ \\
10 & $68.42 \pm 3.75$ & $75.03 \pm 2.21$ & $96.89 \pm 3.37$ \\
5 & $43.89 \pm 2.25$ & $76.74 \pm 3.01$ & $96.33 \pm 2.98$ \\
1.500 & $38.63 \pm 1.79$ & $75.03 \pm 1.73$ & $88.89 \pm 1.89$ \\
0.625 & $8.74 \pm 0.82$ & $16.08 \pm 0.32$ & $44.44 \pm 0.94$ \\
\hline
\end{tabular}

Lupine seed extract was the most effective with $\mathrm{LD}_{50}$ values of $0.55 \%$ after 72 hours and $1.21 \%$ after 48 hours of treatment (Table 5). 
Table 5- LD50 and LD90 values and fiducial limits of lupin seed extract against Callosobruchus maculatus at different times

\begin{tabular}{ccccccc}
\hline $\begin{array}{c}\text { Time of } \\
\text { exposure }(h)\end{array}$ & $n^{a}$ & Slope $\pm S E$ & $\begin{array}{c}\text { LC } 50 \\
\left(\text { Fiducial limit) }^{b}\right.\end{array}$ & $\begin{array}{c}\text { LC90 } \\
\text { (Fiducial limit) }^{b}\end{array}$ & Heterogeneity & $\chi^{2}$ \\
\hline 24 & 360 & $0.166 \pm 0.026$ & 7.26 & 14.98 & 1.22 & 15.98 \\
48 & 360 & $0.151 \pm 0.031$ & $\begin{array}{c}(5.70-9.48) \\
1.21\end{array}$ & $\begin{array}{c}(12.00-21.18) \\
8.06\end{array}$ & 2.32 & 30.27 \\
72 & 360 & $0.193 \pm 0.33$ & $\begin{array}{c}(0.48-1.80) \\
0.55\end{array}$ & $\begin{array}{c}(5.38-20.08) \\
4.98\end{array}$ & 1.65 & 21.33 \\
\hline
\end{tabular}

a: Total number of tested adults; b: $95 \%$ lower and upper fiducial limits

Based on these results, it was observed that the lupin extract demonstrated a high level of insecticidal effect on $C$. maculatus. No previous study on the insecticidal effect of lupin seed extract on $C$. maculatus has been found in the literature. Previously some researchers have indicated that certain plant extracts had insecticidal effects on C. maculatus (Mahdian \& Rahman 2008; Adedire et al. 2011; Cetin \& Elma 2017; Louise et al. 2018).

\subsection{Insecticidal effect of lupin seed extract on Plodia interpunctella (Hubner)}

Lupin seed extract resulted in a low toxic effect on $P$. interpunctella larvae in general. Looking at Table 6, it can see that the death rate was observed just $50 \%$ after 24 hours at a concentration level of $25 \%$ and the highest was recorded $64 \%$ after 72 hours. And with other concentrations, the mortality remained below $40 \%$ for all exposure times.

Table 6- Mortality percent of lupin seed extract against Plodia interpunctella (Hubner) larvae at different concentrations and time of exposure

\begin{tabular}{cccc}
\hline \multicolumn{4}{c}{ Mortality $(\% \pm S E)$} \\
\hline \multirow{3}{*}{ Concentrations $(\% w / w)$} & 24 & Time of exposure $(h)$ \\
\cline { 2 - 4 } & $50.84 \pm 8.42$ & $59.32 \pm 7.19$ & 72 \\
\hline 25 & $28.80 \pm 4.15$ & $42.37 \pm 3.66$ & $64.40 \pm 9.59$ \\
12.50 & $20.33 \pm 7.71$ & $20.33 \pm 3.66$ & $42.37 \pm 1.38$ \\
6.25 & $6.77 \pm 2.77$ & $8.46 \pm 4.15$ & $20.33 \pm 7.71$ \\
3.12 & & & $10.16 \pm 1.38$ \\
\hline
\end{tabular}

The $\mathrm{LD}_{50}$ and $\mathrm{LD}_{90}$ values of lupin extract against the $P$. interpunctella are shown in Table 7. Lupin seed extract showed low toxic effect on $P$. interpunctella adults after 24,48 and 72 hours with $\mathrm{LC}_{50}$ of $23.08 \%, 19.45 \%$ and $18.36 \%$, respectively.

Table 7- LD 50 and LD90 values and fiducial limits of lupin seed extract against Plodia interpunctella at different times

\begin{tabular}{|c|c|c|c|c|c|c|}
\hline $\begin{array}{c}\text { Time of } \\
\text { exposure }(h)\end{array}$ & $n^{a}$ & Slope $\pm S E$ & 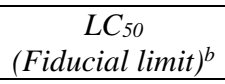 & $\begin{array}{c}L C_{90} \\
(\text { Fiducial limit })^{b}\end{array}$ & Heterogeneity & $\chi^{2}$ \\
\hline 24 & 360 & $0.067 \pm 0.010$ & $\begin{array}{c}23.08 \\
(18.14-33.18)\end{array}$ & $\begin{array}{c}42.12 \\
(32.36-67.07)\end{array}$ & 1.94 & 25.21 \\
\hline 48 & 360 & $0.076 \pm 0.010$ & $\begin{array}{c}19.45 \\
(15.83-25.25)\end{array}$ & $\begin{array}{c}36.33 \\
(29.28-50.82)\end{array}$ & 1.66 & 21.57 \\
\hline 72 & 360 & $0.079 \pm 0.010$ & $\begin{array}{c}18.36 \\
(15.53-22.32)\end{array}$ & $\begin{array}{c}34.58 \\
(29.03-44.24)\end{array}$ & 1.10 & 14.41 \\
\hline
\end{tabular}

a: Total number of tested adults; b: $95 \%$ lower and upper fiducial limits

Bouayad et al. (2013), studies the impact of methanol extracts of ten plants on the growth of the P. interpunctella larvae. They indicated that the growth rate was below $2.5 \%$ for larvae, which were exposed to Ajuga iva, Rosmarinus officinalis, Centaurium erythraea extracts.

There is the restricted number of studies on the insecticidal activity of lupin extract on pests. Isaev (1939), reported that $0.05 \%$ concentration of Lupinus angustifolius was sprayed as a spray on the adults of Nematus ribesii (gooseberry sawfly) (Tenthredinidae- Hymenoptera) and 100\% mortality was observed after 48 hours. In another study, the insecticidal effect of 3 lupin species extracts (L. montanus, L. stipulatus and L. aschenbornii) and the spartein alkaloid obtained from them, was researched on Spodoptera frugiperda larvae. As a result, L. stipulatus extract was found to be the most toxic against the larvae. And also, the extracts of the other two lupin species as well was found to be at least as effective as sparteine (Bermu'dez-Torres et al. 2009). 


\section{Conclusions}

Local lupin seed has high phenol, flavonoid and antioxidant activity. Lupin seed extract showed a toxic effect on Callosobruchus maculatus and Tetranychus urticae. Synthetic pesticides, which are widely used today, are known for causing adverse effects on human beings, the environment, and other creatures. Therefore, especially in the last 15-20 years many studies have been conducted on plants which are known for their biological activities towards pests. From this perspective, further studies that will determine the active ingredients or substances contained in lupin extract that have the insecticidal effect and research the effects of these ingredients on these pests would provide significant findings. It was also concluded that further studies on their acaricidal efficacy under field and greenhouse conditions would provide new findings resulted the potential of lupin seed extract having the potential to be used to manage Tetranychus urticae especially sustainable agriculture and integrated pest management.

\section{References}

Abbott W S (1987). Abbotts Formula - a Method of Computing the Effectiveness of an Insecticide. Journal of American Mosquito Control 3(2):302-303

Adedire C O, Obembe O M, Akinkurolere R O \& Oduleye S O (2011). Response of Callosobruchus maculatus (Coleoptera: Chrysomelidae: Bruchinae) to extracts of cashew kernels. Journal of Plant Diseases and Protection 118(2):75-79

Ali S, Ullah M I, Arshad M, Iftıkhar Y, Saq1b M \& AfzaL M (2017). Effect of botanicals and synthetic insecticides on Pieris brassicae (L., 1758) (Lepidoptera: Pieridae). Turkish Journal of Entomology 41(3): 275-284 (In Turkish) https://doi.org/10.16970/entoted.308941Ashokkumar M, Bhaskaracharya R, Kentish S, Lee J, Palmer M \& Zisu B (2010). The ultrasonic processing of dairy products - An overview. Dairy Science Technology 90(2-3):147-168 https://doi.org/10.1051/dst/2009044

Bermudez-Torres K, Herrera J M, Brito R F, Wink M \& Legal L (2009). Activity of quinolizidine alkaloids from three Mexican Lupinus against the lepidopteran crop pest Spodoptera frugiperda. Biocontrol 54(3):459-466 https://doi.org/10.1007/s 10526-008-9180-y

Blois M S (1958). Antioxidant determination by the use of stable free radicals. Nature, 181: 1199-2000

Bouayad N, Rharrabe K, Ghailani N N, Jbilou R, Castanera P \& Ortego F (2013). Insecticidal effects of Moroccan plant extracts on development, energy reserves and enzymatic activities of Plodia interpunctella. Spanish Journal of Agricultural Research 11(1):189-198

Buszewski B, Rafinska K, Cvetanovic A, Walczak J, Krakowska A, Rudnicka J \& Zekovic Z (2019). Phytochemical analysis and biological activity of Lupinus luteus seeds extracts obtained by supercritical fluid extraction. Phytochemistry Letters 30:338-348 https://doi.org/10.1016/j.phytol.2019.02.014

Cetin H \& Elma F N (2017). Effects of some plant extracts on adults of Cowpea weevil [Callosobruchus maculatus F. (Coleoptera: Chrysomelidae)]. Harran Journal of Agricultural and Food Science 21(4): 404-411

Chen Y J \& Dai G H (2017). Effect of the extract and compound from Solanum nigrum Linn on Tetranychus cinnabarinus. Journal of Applied Entomology 141(6):458-469 https://doi.org/10.1111/jen.12358

Duke J A (1992). Natural Medicines are Natural Pesticides? In: Nigg HN \& Seigler D (Eds) Phytochemical Resources for Medicine and Agriculture, Springer US, Boston, MA, pp. 237-245

Duranti M, Consonni A, Magni C, Sessa F \& Scarafoni A (2008). The major proteins of lupin seed: Characterisation and molecular properties for use as functional and nutraceutical ingredients. Trends Food Science Technology 19(12):624-633

Elma F N (2014). Screening of some medicinal and aromatic plant extracts for their insecticidal efficacies. II. International Conference on Environmental Science and Technology, 14-17 May, Antalya, pp. 365

Erdoğan P, Yildirim A \& Sever B (2012). Investigations on the Effects of Five Different Plant Extracts on the Two-Spotted Mite Tetranychus urticaee Koch (Arachnida: Tetranychidae). Hindawi Publishing Corporation Psyche https://doi.org/10.1155/2012/125284

Gegear R J, Manson J S \& Thomson JD (2007). Ecological context influences pollinator deterrence by alkaloids in floral nectar. Ecology Letters 10:375-382 https://doi.org/10.1111/j.1461-0248.2007.01027.x

Gökçe A, Whalon M E, Çam H, Yanar Y, Demirtaş İ \& Gören N (2007). Contact and residual toxicities of 30 plant extracts to Colorado potato betle larvae. Archives of Phytopathology and Plant Protection 40(6): 441-450 https://doi.org/10.1080/03235400600628013

Isaev S I (1939). Insecticidal activitiy of Lupinus angustifolius L. Trudy Belorusskogo Sel'skokhoz Institut 8, 119

Kalogeropoulos N, Chiou A, Ioannou M, Karathanos V T, Hassapidou M \& Andrikopoulos N K (2010). Nutritional evaluation and bioactive microconstituents (phytosterols, tocopherols, polyphenols, triterpenic acids) in cooked dry legumes usually consumed in the Mediterranean countries. Food Chemistry 121(3):682-690

Karamac M, Orak H H, Amarowicz R, Orak A \& Piekoszewski W (2018). Phenolic contents and antioxidant capacities of wild and cultivated white lupin (Lupinus albus L.) seeds, Food Chemistry, 258: 1-7

LeOra Software (1987). Polo-PC a User's Guide to Probit or Logit Analysis, 1119 Shattuck Avenue, Berkeley, CA, USA

Louise K M, Habiba K, Sidonie F T \& Tchuenguem Fohouo F N (2018). Management of Callosobruchus maculatus F. (Coleoptera: Bruchidae) using methanol extracts of Carica papaya, Carissa edulis, Securidaca longepedonculata and Vinca rosea and impact of insect pollinators on cowpea types. Journal of Entomology and Zoology Studies 6(2): 1017-1027

Mahdian S H A \& Rahman M K (2008). Insecticidal effect of some spices on Callosobruchus maculatus (Fabricius) in black gram seeds. Rajshahi University Zoology Society 27: 47-50

Oomah B D, Tiger N, Olson M \& Balasubramanian P (2006). Phenolics and antioxidative activities in narrow-leafed lupins (Lupinus angustifolius L.). Plant Foods Human Nutrition 61(2): 91-97 https://doi.org/10.1007/s11130-006-0021-9

Philippi J, Schliephake E, Jürgens H-U, Jansen G \& Ordon F (2016). Correlation of the alkaloid content and composition of narrow-leafed lupins (Lupinus angustifolius L.) to aphid susceptibility. Journal Pest Science 89(2): 359-373

Reinhard H, Rupp H, Sager F, Streule M \& Zoller O (2006). Quinolizidine alkaloids and phomopsins in lupin seeds and lupin containing food. Journal of Chromatografy A 1112(1-2): 353-360 https://doi.org/10.1016/j.chroma.2005.11.079

Sertkaya E, Kaya K \& Soylu S (2010). Acaricidal activities of the essential oils from several medicinal plants against the carmine spider mite (Tetranychus cinnabarinus Boisd.) (Acarina: Tetranychidae). Industrial Cropa and Production 31(1):107-112

Siger A, Czubinski J, Kachlicki P, Dwiecki K, Lampart-Szczapa E \& Nogala-Kalucka M (2012). Antioxidant activity and phenolic content in three lupin species. Journal of Food Composition and Analysis 25(2):190-197 https://doi.org/10.1016/j.jfca.2011.10.002 
Singleton V L \& Rossi J A (1965). Colorimetry of total phenolics with phosphomolybdic-phosphotungstic acid reagents. American Journal of Enology and Viticulture, 16: 144-158

Topakcı N, İkten C \& Göçmen H (2005). A Research on Some Effects of Inula viscosa (L.) Ait (Asteraceae) leaf extract on Carmine Spider Mite, Tetranychus cinnabarinus (Boisd.) (Acari:Tetranychidae). Mediterranean Agricultural Sciences 18(3): 411-415 (In Turkish)

Topuz E \& Madanlar N (2011). Contact and repellency effects of some plant essential oils against Tetranychus cinnabarinus (Boisduval, 1867) (Acari: Tetranychidae). Turkish Bulletin of Entomology 1(2): 99-107 (In Turkish)

Tunc I \& Sahinkaya S (1998). Sensitivity of two greenhouse pests to vapours of essential oils. Entomol Expermentalis et Applicata 86(2):183187 https://doi.org/10.1046/j.1570-7458.1998.00279.x

Tüzün A E (2013). An Alternative Source of Protein Lupin (Lupinus L.) Use of Broiler Nutrition. Journal of Animal Production 54(1): 50-54 (In Turkish)

Wink M (1992). The role of quinolizidine alkaloids in plant insect interactions, pp. 133-169, in E. A. Bernays (ed.) Insect-Plant İnteractions, Vol: IV, CRC press, Florida

Yildiz S (2011). Rotational and nematicidal effect of lupine (Lupinus albus L.: Leguminosae). African Journal of Biotechnology 10(61):1325213255 https://doi.org/10.5897/AJB11.1881

(C) 2021 by the authors. Licensee Ankara University, Faculty of Agriculture, Ankara, Turkey. This article is an open access article distributed under the terms and conditions of the Creative Commons Attribution (CC BY) license (http://creativecommons.org/licenses/by/4.0/). 